\title{
Inventory of Determinants of Obesity-Related Behaviors in Adolescents: Development and Psychometric Characteristics
}

\author{
Parisa Amiri ${ }^{1}$; Fazlollah Ghofranipour ${ }^{2, *}$; Sara Jalali-Farahani ${ }^{1}$; Fazlollah Ahmadi ${ }^{3}$; Farhad \\ Hosseinpanah ${ }^{4}$; Haidar Ali Hooman ${ }^{5}$; Parnian Parvin ${ }^{1,6}$; Mohammadreza Ghasemi ${ }^{1,6}$ \\ ${ }^{1}$ Research Center for Social Determinants of Endocrine Health, Obesity Research Center, Research Institute for Endocrine Sciences, Shahid Beheshti University of Medical Sciences, \\ Tehran, IR Iran \\ ${ }_{3}^{2}$ Department of Health Education, Tarbiat Modares University, Tehran, IR Iran \\ 3 Department of Nursing, Tarbiat Modares University, Tehran, IR Iran
4 Obesity Research Center, Research Institute for Endocrine Sciences, Shahid Beheshti University of Medical Sciences, Tehran, IR Iran \\ ${ }^{5}$ Department of Psychology, Shahid Beheshti University, Tehran, IR Iran \\ 6 Students' Research Committee, Shahid Beheshti University of Medical Sciences, Tehran, IR Iran \\ ${ }^{*}$ Corresponding author: Fazlollah Ghofranipour, Department of Health Education, Tarbiat Modares University, P. O. Box: 14115-111, Tehran, IR Iran. Tel: +98-2182883869, \\ E-mail:ghofranf@modares.ac.ir
}

Received: October 18, 2014; Revised: April 8, 2015; Accepted: May 13, 2015

\begin{abstract}
Background: The rising prevalence of childhood obesity is a major health problem worldwide. Hence, there is a growing need for health professionals to become capable of assessing the factors that determine lifestyle in a culturally relevant manner.

Objectives: This study aimed to develop and assess a questionnaire for measuring determinants of obesity-related behaviors in Tehranian adolescents.

Patients and Methods: Based on the results of a qualitative study and an extensive literature review, the 44-item "Inventory of determinants of obesity-related behaviors in adolescents (IDOBA)" with eight subscales was developed:1) unhealthy nutrition and physical inactivity; 2) stress-related eating; 3) perceived inability; 4) perceived lack of threat; 5) perceived priority of educational achievement; 6) perceived acceptability; 7) motivation loss; and 8) lack of support. Validity of IDOBA was assessed, utilizing face, content, and construct validity methods. To confirm face validity, ten overweight/obese adolescents completed the questionnaire. To calculate content validity ratio (CVR) and content validity index (CVI), a different panel of ten experts commented independently on the necessity, relevance, clarity, and simplicity of each item. To assess construct validity using exploratory factor analysis (EFA), a total of 478 adolescents (57.7\% male) aged 13 to 18 years, who were recruited from schools, participated in the study. Confirmatory factor analysis (CFA) was used to test whether the data fit the hypothesized measurement model that was derived from EFA. Test-retest and internal consistency methods were used to assess reliability of the IDOBA scale.

Results: All items were perceived as relevant and comprehendible by adolescents. Content validity was confirmed by the panel of experts. The internal consistency, as measured by Cronbach's alpha coefficients, exceeded the minimum reliability standard of 0.60 for eight subscales. No ceiling effects were observed. Detected floor effects ranged from $0.2 \%$ for perceived acceptability subscale score to $18.8 \%$ for lack of threat subscale score. The EFA suggested an eight-factor construct and the results of the CFA indicated acceptable fit indices for the proposed model. All subscales demonstrated satisfactory test-retest reliability (intra-class correlation coefficient, 0.42 - 0.91 ) over one month.

Conclusions: Results provided initial evidence that the IDOBA is a valid and reliable instrument for measuring determinants of obesityrelated behaviors in Iranian adolescents, indicating that the questionnaire can be used in future weight management programs for
\end{abstract} Tehranian adolescents.

Keywords: Obesity; Adolescent; Validity; Reliability; Iran

\section{Background}

The rising prevalence of childhood obesity is a major health problem worldwide $(1,2)$. Increasing evidence reveals that overweight children are at increased risk for various chronic diseases later in life (3). The latest national data in the United States suggest a 17\% prevalence of childhood obesity (4). In Iran according to the childhood and adolescence surveillance and prevention of Iranian adult non-communicable disease (CASPIAN) study, more than $8.8 \%$ of school-age children are presently overweight and another $4.5 \%$ are obese (5). Additionally, findings of recent cross-sectional studies conducted in Tehran indicated that overweightness and obesity are highly prevalent among adolescents residing in Tehran $(6,7)$. In the study conducted by Hatami et al. on 1157 adolescents, $20.7 \%$ were overweight or obese (6). Another study by Jalali-Farahani et al. on 465 high school students showed that $38.5 \%$ of them were overweight or obese (7). These findings have led to a widely held view that pediatric obesity interventions are urgently required.

Behavioral strategies are considered the first line of

Copyright (C) 2015, Research Institute For Endocrine Sciences and Iran Endocrine Society. This is an open-access article distributed under the terms of the Creative Commons Attribution-NonCommercial 4.0 International License (http://creativecommons.org/licenses/by-nc/4.0/) which permits copy and redistribute the material just in noncommercial usages, provided the original work is properly cited. 
implementation for obesity prevention in the early years of life (8). Previous quantitative studies in Iran primarily have described obesity-related behaviors in adolescents, without much insight to why they are engaged in such behaviors (9-11). Accordingly, there are related reviews demonstrating significant numbers of youth obesity interventions that have demonstrated modest results so far (12-14). Hence, there is a growing need for health professionals to become capable of assessing the factors that determine lifestyle in a culturally relevant manner.

There are several instruments already developed to assess lifestyle in children and adolescents (15-18); however, prior to the Inventory Determinants of Obesity-Related Behaviors in Adolescents (IDOBA), there was no known instrument to assess the culturally relevant determinants of obesity-related behaviors in Iranian adolescents. The IDOBA was developed to fill the gap in current literature available on measures previously developed.

\section{Objectives}

This study aimed to develop and assess validity and reliability of the IDOBA, in a diverse sample of overweight and obese adolescent residents of Tehran, Iran.

\subsection{The Conceptual Framework}

The conceptual framework for this study was based on the results of a qualitative research, using a grounded theory approach with participation of 51 overweight/ obese adolescents (19). This framework hypothesizes that influenced by socio-environmental factors and personal characteristics, predisposing beliefs in adolescents form the basis, which results in their unhealthy lifestyles. These beliefs include perception of educational achieve- ment priority, acceptability, lack of threat, and inability to control weight, which induces a psychologic condition that decreases adolescent motivation towards healthy behaviors (Figure 1).

\section{Patients and Methods}

\subsection{Subjects and Settings}

Subjects were adolescents, aged 13 to 18 years. To maximize the heterogeneity of the sample, subjects were recruited from schools of two diverse socio-economic areas of Tehran, Iran, one located in the north of Tehran, where the socio-economic status of people is mostly high, and the other, in the south of the city with low socio-economic status. These schools were informed of the study protocol and goals. Inclusion criteria were age of 13 to 18 years and being overweight or obese; an exclusion criterion was presenting with complaint of some obesity-related diseases such as thyroid disorders, based on adolescents' reports. Participants were recruited from these schools and written parental informed consent and child assent were obtained. Overweightness and obesity were assessed by body mass index (BMI), calculated as weight in kilograms divided by square of height in meters. Based on the standardized percentile curves of BMI, suggested for Iranian children and adolescents, overweightness and obesity were defined as BMI of $\geq 85$ th to $<95$ th percentile, and more or equal than 95th percentile, respectively (20). Weight and height were measured with participants wearing light clothes and without shoes, using standard apparatus. Weight was measured to the nearest $0.1 \mathrm{~kg}$ on a calibrated beam scale (Seca 707; range, 0.1 - $150 \mathrm{~kg}$;

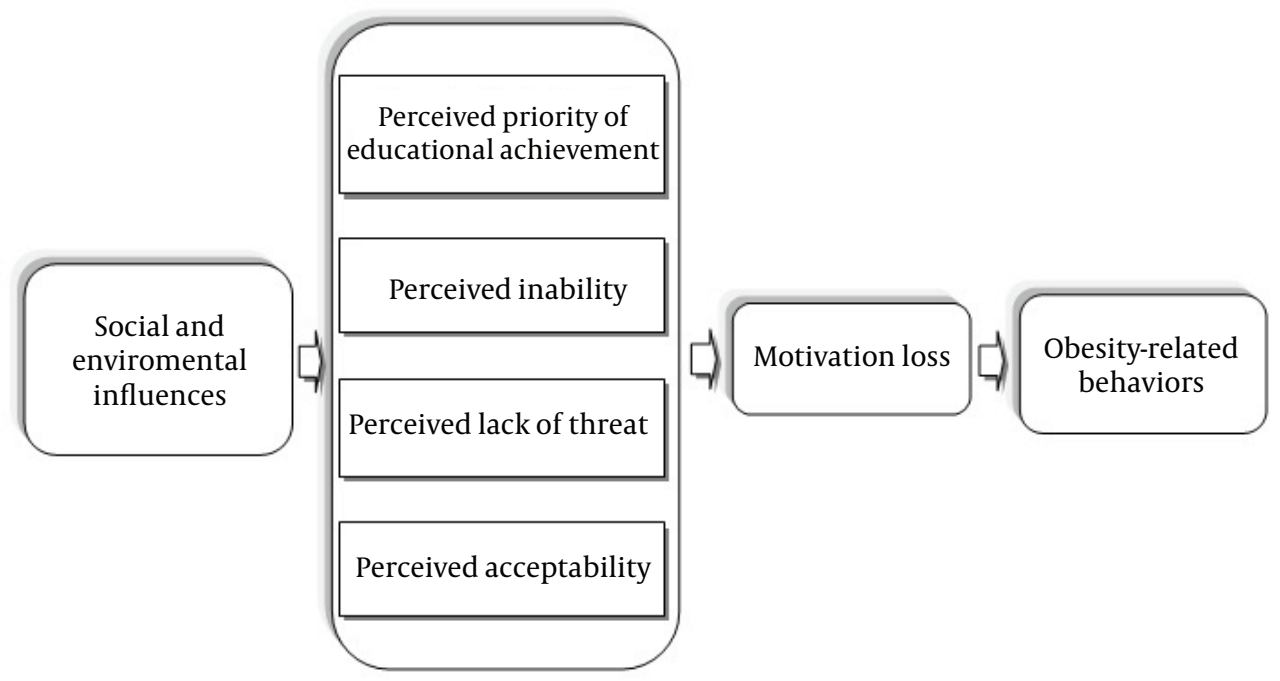

Figure 1. Conceptual Framework of Weight Gain Process in Studied Adolescents 
Amiri P et al.

Hanover, MD, Germany). To measure height, a rigid tape measure was fixed to the wall, while the participant stood with heels, buttocks, shoulders, and occiput touching the vertical tape. All measurements were taken by the same person to eliminate subjective error. Adolescents completed the IDOBA themselves and a research assistant was available to answer their questions, after the instructions had been clarified. The scientific research committee of the Tarbiat Modares University (TMU), Tehran, Iran, approved the study.

\subsection{Measures}

\subsubsection{Inventory of Determinants of Obesity-Related Be- haviors in Adolescents}

The 44-item IDOBA, developed through a qualitative study, encompasses the followings: 1) Unhealthy nutrition and physical inactivity; 2) Stress-related behaviors; 3) Perceived inability; 4) Perceived lack of threat; 5) Perceived priority of educational achievement; 6) Perceived acceptability; 7) Motivation loss; and 8) Lack of support.

\subsubsection{Inventory of Determinants of Obesity-related Be- haviors in Adolescents; Information Form}

The IDOBAinformation form, completed by adolescents, contained demographic information on the adolescents and their families. It also asked about the adolescent's chronic diseases, which could have affected or resulted in their obesity-related behaviors or weight gain during the past six months. Furthermore, it included questions about their experiences regarding weight control and their satisfaction with the outcomes of previous efforts to lose weight.

\subsection{Scale Development Procedure}

Scale development began with concept identification, and is followed by different steps including concept analysis, item writing, face and content validity, reliability assessment, and construct validity assessment (21). Accordingly, each of the theory constructs were transformed to lower level concepts and then stated as variables in quantitative terms, using the results of the initial qualitative study and literature review. Considering the theoretical definition and attributes of the concept derived from the first step, an initial blueprint consisting of 91 items was generated. Each item was rated on a five-point Likert scale anchored at one to five (always to never and strongly agree to strongly disagree).

Validity of IDOBA was assessed by face, content, and construct validity methods. To confirm face validity, ten overweight/obese adolescents completed the questionnaire and provided information such as whether the initial items were relevant to them and if so, how important each issue was in their daily lives. Regarding qualitative content validity, an expert panel of ten specialists in health education, endocrinology, nutrition, psychology, and physical activity examined the initial questionnaire. The panel was asked to comment on individual items in relation to the accuracy and style. Items were modified based on the experts' comments. To calculate content validity ratio (CVR) and content validity index (CVI), a different panel of ten experts was asked to comment independently on the necessity, relevance, clarity, and simplicity of each item. The necessity of the items was assessed using a three-point rating scale: 1 , not necessary; 2 , useful, but not essential; and 3, essential. Following the experts' assessments, a CVR for total scale was computed, according to Lawshe scores (22). The relevance of the items was also assessed, using a four-point rating scale: 1 , not relevant; 2 , slightly relevant; 3, relevant; and 4, completely relevant. The CVI of each question was determined by the proportion of experts rating the item as more or equal than 3 (23). After performing construct validity and detection of IDOBA subscales, the reliability was assessed, using internal consistency reliability and test-retest. For the test-retest reliability of the scale, it was re-administered to 56 individuals one month after the first completion. The average length of time it took for subjects to complete the test was 20 minutes.

\subsection{Statistical Analysis}

Range of measurement was based on the percentage of scores at the extremes of the scaling range, ie, the maximum (ceiling effect) and the minimum (floor effect) possible scores (24). Reliability of scale internal consistency was determined by calculating Cronbach's Alpha coefficient. Values $>0.6$ were considered as satisfactory. The test-retest reliability of the scale was evaluated using the intra-class correlation coefficient (ICC), and ICCs > 0.6 were considered acceptable.

Exploratory factor analysis (EFA) was used to assess construct validity and derivate IDOBA subscales. KaiserMeyer-Olkin (KMO), measure of sampling adequacy, Bartlett's test of sphericity, and total variance explained were used for the evaluation of model adequacy. The EFA was performed by the extraction method of principal component analysis, utilizing Varimax rotation with Kaiser normalization. In this analysis, loadings over cutoff values of 0.3 were considered as important and the items remaining in the model were based on this criterion. Confirmatory factor analysis (CFA) was performed to test whether the data fit the hypothesized measurement model, which was extracted by EFA. Weighted least squares (WLS) estimation method was used at CFA. Asymptomatic covariance matrix was considered as a weighted matrix. Goodness-of-fit indices (GFIs) and reasonable threshold levels of these indices for CFA were considered as $\chi^{2} / \mathrm{df}<3$, root mean square error of approximation (RMSEA) and standardized root mean 
square residual (SRMR) $<0.08$ as well as comparative fit index (CFI), goodness-of-fit index (GFI), and normed fit index $(\mathrm{NFI})>0.9$ (25). Statistical analysis was performed using SPSS 22.0 (SPSS Inc., Chicago, Illinois, the United States) and LISREL 8.80 (Scientific Software International Inc, 2007).

\section{Results}

A total of 478 adolescents ( $57.7 \%$ male) aged 13 to 18 years participated in the study. Mean BMI was $30.25 \pm 4.22 \mathrm{~kg} /$ $\mathrm{m}^{2}$. Levels of education, occupation status of parents, and their mean age are reported in Table 1. Most fathers and mothers were educated up to secondary levels (38.1\% and $50.1 \%$, respectively). Most fathers had non-governmental jobs (64.6\%), whereas the highest proportions of mothers were House wife (79.9\%).

Based on the face validity results, all questionnaire items were generally easy to read and understand for adolescents; however, a few words were changed to meet participants' considerations. Of 91 items, 89 (97.8\%) were labeled as "important" to them. Qualitative content validity was confirmed by the panel of experts and findings regarding the CVR and CVI confirmed the quantitative content validity of 75 items. The CVR in this study for total scale was 0.82 , indicating a satisfactory result. A satisfactory level of agreement was found (CVI = 0.92) among panelists suggesting that the scale had a good content validity. No floor effects were observed. Detected ceiling effects ranged from $2.7 \%$ for perceived priority of educational achievement subscale score to $12.9 \%$ for stress-related eating.

In case of EFA, KMO showed a reasonable fit of the model $(\mathrm{KMO}=0.78)$, and the Bartlet's test confirmed the sphericity assumption $\left(\chi^{2}=5469.4, \mathrm{df}=946\right.$, and $\mathrm{P}$ $<0.001)$. The extracted eight factors were based on eigenvalues $>1.25$. The percentage of the total variance was $49.06 \%$ by the rotated eight factors. Factor loadings and explained variance of each factor are illustrated in Table 2. All items were loaded between 0.30 and 0.89 on their corresponding factors. The results of the CFA for eight-factor hypothesized model are reported in Table 3 and indicate acceptable fit of the proposed model. Minimum factor loadings was $0.12(t=6.56)$ for question number 7 (from the unhealthy nutrition and physical activity subscale) and maximum factor loadings was $0.99(t=33.88)$ for question number 14 (from the perceived inability subscale).

The mean of subscale scores and number of items in each subscale are presented in Table 4. To calculate subscale scores, all items in the corresponding subscale were summed and transformed to a zero to 100 scale. No ceiling effects were observed. Detected floor effects ranged from $0.2 \%$ for perceived acceptability subscale score to $18.8 \%$ for lack-of-threat subscale score. The Cronbach's alpha was calculated for each subscale and ranged from 0.61 to 0.81 . Minimum and maximum ICC of items in each subscale are reported in Table 4 ; question No. 16 from the perceived acceptability subscale had low ICC, which could be due to the long interval between test and retest measurement.

Table 1. Demographic Characteristics of Adolescents and Their Parents ${ }^{a}$

\begin{tabular}{lc}
\hline Variables & Values $^{\mathrm{b}}$ \\
\hline Sex & $202(42.3)$ \\
\hline Female & $276(57.7)$ \\
\hline Male & \\
\hline Grade & $180(37.7)$ \\
$1^{\text {st }}$ grade & $123(25.7)$ \\
$2^{\text {nd }}$ grade & $122(25.5)$ \\
$3^{\text {rd }}$ grade & $53(11.1)$ \\
$4^{\text {th }}$ grade & \\
\hline
\end{tabular}

Fathers' level of education

$\begin{array}{lc}\text { Primary } & 112(24.1) \\ \text { Secondary } & 177(38.1) \\ \text { Higher } & 176(37.8)\end{array}$

Mothers' level of education

\begin{tabular}{lc} 
Primary & $113(23.9)$ \\
\hline Secondary & $237(50.1)$ \\
\hline Higher & $123(26.0)$ \\
\hline
\end{tabular}

\section{Fathers' occupation}

$\begin{array}{lc}\text { Governmental job } & 115(24.7) \\ \text { Non-governmental job } & 301(64.6) \\ \text { Unemployed } & 12(2.6) \\ \text { Retired } & 38(8.1)\end{array}$

\begin{tabular}{|lc}
\hline Mothers' occupation & \\
\hline Governmental job & $30(10.6)$ \\
\hline Non-governmental job & $34(7.2)$ \\
\hline House wife & $377(79.9)$ \\
\hline Retired & $11(2.3)$ \\
\hline Body mass index, $\mathbf{~ k g / \mathbf { m } ^ { 2 }}$ & $30.25 \pm 4.22$ \\
\hline Fathers' age, $\mathbf{y}$ & $47.75 \pm 6.31$ \\
\hline Mothers' age, $\mathbf{y}$ & $41.67 \pm 5.53$ \\
\hline
\end{tabular}

a The total number of participants was 478 .

$\mathrm{b}$ Values are presented as No. (\%) or mean \pm SD. 
Amiri P et al.

Table 2. Factor Analysis Results for the Inventory of Determinants of Obesity-related Behaviors in Adolescents

\begin{tabular}{|c|c|c|c|c|c|c|c|c|}
\hline \multirow[t]{2}{*}{ Questions } & \multicolumn{8}{|c|}{ Subscales } \\
\hline & $\mathbf{1}$ & 2 & 3 & 4 & 5 & 6 & 7 & 8 \\
\hline \multicolumn{9}{|c|}{ Lack of support } \\
\hline Q42 & 0.703 & & & & & & & \\
\hline Q41 & 0.666 & & & & & & & \\
\hline Q38 & 0.650 & & & & & & & \\
\hline Q43 & 0.597 & & & & & & & \\
\hline Q37 & 0.556 & & & & & & & \\
\hline Q40 & 0.549 & & & & & & & \\
\hline Q34 & 0.545 & & & & & & & \\
\hline Q39 & 0.538 & & & & & & & \\
\hline Q44 & 0.521 & & & & & & & \\
\hline Q35 & 0.480 & & & & & & & \\
\hline Q36 & 0.434 & & & & & & & \\
\hline \multicolumn{9}{|c|}{ Motivation loss } \\
\hline Q30 & & 0.724 & & & & & & \\
\hline Q32 & & 0.691 & & & & & & \\
\hline Q33 & & 0.676 & & & & & & \\
\hline Q31 & & 0.662 & & & & & & \\
\hline Q28 & & 0.630 & & & & & & \\
\hline Q27 & & 0.576 & & & & & & \\
\hline Q29 & & 0.383 & & & & & & \\
\hline \multicolumn{9}{|c|}{ Perceived priority of educational achievement } \\
\hline Q24 & & & 0.751 & & & & & \\
\hline Q23 & & & 0.735 & & & & & \\
\hline Q25 & & & 0.716 & & & & & \\
\hline Q22 & & & 0.575 & & & & & \\
\hline Q26 & & & 0.432 & & & & & \\
\hline \multicolumn{9}{|c|}{ Unhealthy nutrition and physical inactivity } \\
\hline Q3 & & & & 0.665 & & & & \\
\hline Q1 & & & & 0.595 & & & & \\
\hline Q2 & & & & 0.578 & & & & \\
\hline Q4 & & & & 0.573 & & & & \\
\hline Q8 & & & & 0.495 & & & & \\
\hline Q7 & & & & 0.471 & & & & \\
\hline Q5 & & & & 0.441 & & & & \\
\hline Q6 & & & & 0.410 & & & & \\
\hline
\end{tabular}

Perceived acceptability

$\begin{array}{lr}\text { Q17 } & 0.730 \\ \text { Q15 } & 0.676 \\ \text { Q16 } & 0.654 \\ \text { Q19 } & 0.588 \\ \text { Q18 } & 0.556\end{array}$

Perceived inability

$\begin{array}{lr}\text { Q14 } & 0.885 \\ \text { Q13 } & 0.872 \\ \text { Q12 } & 0.401\end{array}$

Stress-related eating

Q11

Q10

Q9

Perceived lack of threat

Q21

Q20

Explained variance

8.38

0.872

0.401 
Amiri P et al.

Table 3. Results of Confirmatory Factor Analysis for the Eight-Factor Model ${ }^{\text {a }}$

\begin{tabular}{lcccccccc}
\hline Model & $\chi^{2}$ & df & $\chi^{2} / \mathbf{d f}$ & RMSEA & CFI & GFI & NFI & SRMR \\
\hline Values & 2178.53 & 874 & 2.49 & 0.056 & 0.99 & 0.92 & 0.99 & 0.071 \\
\hline $\begin{array}{l}\text { a Abbreviations: CFI, comparative fit index; df, degree of freedom; GFI, goodness fit index; } \\
\text { approximation; normal fit index; RMSEA, root mean square error of }\end{array}$
\end{tabular}

Table 4. Statistics for Inventory of Determinants of Obesity-related Behaviors in Adolescents ${ }^{\text {a }}$

\begin{tabular}{|c|c|c|c|c|c|c|c|}
\hline & \multirow[t]{2}{*}{ Number of Items } & \multirow[t]{2}{*}{ Mean \pm SD } & \multirow[t]{2}{*}{ Ceiling } & \multirow[t]{2}{*}{ Floor } & \multirow[t]{2}{*}{ Cronbach's $\alpha$} & \multicolumn{2}{|c|}{ Test-Retest } \\
\hline & & & & & & Min & Max \\
\hline $\begin{array}{l}\text { Unhealthy nutrition } \\
\text { and physical inactivity }\end{array}$ & 8 & $50.2 \pm 12.6$ & 0 & 0 & 0.66 & 0.68 & 0.91 \\
\hline Stress-related eating & 3 & $44.0 \pm 17.8$ & 0.8 & 12.6 & 0.61 & 0.64 & 0.79 \\
\hline Perceived inability & 3 & $62.2 \pm 20.9$ & 0 & 0 & 0.67 & 0.70 & 0.84 \\
\hline Perceived lack of threat & 2 & $49.8 \pm 23.6$ & 6.5 & 18.8 & 0.62 & 0.60 & 0.80 \\
\hline $\begin{array}{l}\text { Priority of educational } \\
\text { achievement }\end{array}$ & 5 & $52.9 \pm 20.2$ & 1.5 & 6.7 & 0.74 & 0.59 & 0.78 \\
\hline Perceived acceptability & 5 & $73.8 \pm 17.9$ & 6.1 & 0.2 & 0.73 & 0.42 & 0.80 \\
\hline Motivation loss & 7 & $46.4 \pm 17.5$ & 0.4 & 5.6 & 0.80 & 0.61 & 0.87 \\
\hline Lack of support & 11 & $49.1 \pm 16.8$ & 0 & 4 & 0.81 & 0.60 & 0.80 \\
\hline
\end{tabular}

a The total number of participants was 478 .

\section{Discussion}

Our results indicated that the IDOBA facilitates a reliable and valid measurement of determinants of obesityrelated behaviors in Tehranian adolescents. Its internal consistency reliabilities generally exceeded the standard of 0.70 , and all subscales demonstrated satisfactory testretest reliability, consistent with other similar self-reporting measures $(17,26,27)$.

Research on explanations of the obesity-related behaviors process in adolescents has been less extensive than that on description of these behaviors, as it is hindered by a lack of related conceptual frameworks. Accordingly, there is a lack of empirical instruments to assess lifestyle determinants in the earlier years of life. Among the available instruments, each of the adolescent life style questionnaire (ALQ) and the Adolescent Lifestyle Profile (ALP) focus on seven domains of a healthy life style in adolescents $(16,17)$. Moreover, a recently reported questionnaire, HABITS, was developed to assess pediatric lifestyle and weight management by measuring children's food intake and physical activity/sedentary behavior (15). There is also another instrument, the Life Style Behavior Checklist (LBC), developed to measure parents' challenges faced in managing their children behaviors and how these challenges might be addressed in treatment (18).

As a theory-based questionnaire, the IDOBA differs from the earlier mentioned instruments, which focused mainly on measuring sedentary behaviors or barriers to healthy lifestyles in children and adolescents. Recent evidence about moderate goal achievements of childhood obesity prevention programs indicates that these efforts should be based on culture related knowledge (12-14). Based on this premise, all items of the IDOBA were designed and developed to measure potential factors that contribute to de- creased adolescent motivation regarding healthy behaviors according to a context-based conceptual framework. This framework indicates the central role of motivation loss that results in obesity-related behaviors and excessive weight gain in adolescents in Tehran. This motivation loss could be a result of adolescents' beliefs and perceptions, including prioritized educational achievement, acceptability, inability for weight control, and lack of threat, which are affected by certain socio-environmental and personal characteristic (19). However, the items of the IDO$\mathrm{BA}$ are not unique to Iranian adolescents and could be relevant for other ethnic groups, which would require basic but essential assessments.

The IDOBA is a simple instrument, which is developed for researchers and healthcare professionals to assist in identifying the underpinning factors of obesity-related behaviors in adolescents in Tehran and to developing prevention programs to overcome barriers to a healthy lifestyle. However, the generalizability of the current findings are limited for the following reasons:

1) The participants of this study were limited to urban Tehranian adolescents; 2) The information of nonparticipants was not available; and 3) Due to limited access to socio-economic data, the studied population could not be considered as a representative sample of adolescents from different socio-economic statuses in Tehran.

In conclusion, the IDOBA was designed to measure determinants of obesity-related behaviors in adolescents, based on the conceptual constructs that emerged from the initial qualitative study and a literature review. To confirm its current validity results, further evaluation with larger Iranian rural and urban populations with different socio-economic statuses is recommended. 
Box 1. The inventory of determinants of obesity-related behaviors in adolescents (IDOBA)

Factor 1: Unhealthy nutrition and physical inactivity

1. I have high calorie foods (sandwich, pizza, French fries, cake, chips, and doughnut) for lunch and dinner.

2. I have high calorie foods and drinks (sandwich, cake, chips, chocolate, cheese puffs, ice cream, doughnut, and sugary sodas) as snacks.

3. I drink sugary sodas with lunch and dinner.

4. I have mayonnaise with lunch and dinner.

5. I have high calorie foods and snacks with friends in social gatherings.

6. I watch TV for more than 2 hours per day.

7. I go online or play video games for more than 2 hours a day.

8. I spend more than 2 hours a day with my friends on the phone.

Factor 2: Stress-related eating

9. I eat while studying and doing my homework.

10. I overeat when I am excited or stressed.

11. I overeat when I have nothing to do.

Factor 3: Perceived Inability

12. I do not try to lose weight, because I believe obesity is hereditary.

13. I do not try to lose weight, because I am not satisfied with the amount of weight I lose.

14. I do not try to lose weight, because I am not satisfied with the speed of my weight loss.

Factor 4: Perceived Acceptability

15. I can exercise as much as my peers can.

16. I believe that I receive as much attention as my peers do.

17. I can wear my favorite clothes like my peers.

18. I am satisfied with who I am.

19. I feel comfortable among people.

Factor 5: Perceived Lack of Threat

20. I worry about my weight when I see obese relatives suffer from diseases.

21. I worry about my weight because of serious consequences of obesity and dangerous related diseases.

Factor 6: Perceived Priority of Educational Achievement

22. I do not start a diet because it affects my studies and I do not do as well.

23. I do not exercise because it takes away from my study time.

24. I cannot lose weight because of school exams

25. I cannot lose weight because of educational competition with my friends

26. I do not exercise when I am too tired or do not feel like it.

Factor 7: Motivation Loss

27. I intend to lose weight during the next 6 months.

28. I intend to decrease my intake of fatty and sweet foods during next 10 days.

29. I intend to start exercising regularly during next 10 days.

30. I will follow my weight loss diet even if it is difficult.

31. I do not overeat even if nobody is monitoring my eating.

32. I reject my friend's food offers to lose weight.

33. I maintain the weight that I have lost

Factor 8: Lack of Support

34. I cannot lose weight because my parent do not prepare low calorie foods for me

35. I cannot go for walking or exercise because my parents do not accompany me

36. Media advertisements motivate me to consume fatty and sweet foods

37. I have no access to the information necessary for weight loss

38. I cannot exercise because of the limited space in our house

39. I cannot exercise in public places because this not common

40. I cannot lose weight because our school food buffet doesn't offer healthy snacks

41. I cannot go on diet because healthy foods like fruits and meats are expensive

42. I cannot exercise because of the high cost of exercise classes.

43. I cannot exercise because the exercise classes are either too far away or the class times do not coordinate with my schedule.

44. I cannot exercise because of heavy traffic and air pollution 


\section{Acknowledgements}

We would like to appreciate the cooperation of all study participants. We also gratefully acknowledge assistance of Dr. Mohammad Asghari Jafarabadi in statistical analysis. The authors wish to acknowledge Ms. Niloofar Shiva for critical editing of English grammar and syntax of the manuscript.

\section{Authors' Contributions}

Study concept and design: Parisa Amiri, Fazlollah Ghofranipour, and Fazlollah Ahmadi. Acquisition of data: Parisa Amiri and Sara Jalali-Farahani. Analysis and interpretation of data: Parisa Amiri and Haidar Ali Hooman. Drafting the manuscript: Parisa Amiri, Sara Jalali-Farahani, Parnian Parvin, and Mohammadreza Ghasemi. Critical revision of the manuscript for important intellectual content: Fazlollah Ghofranipour, Fazlollah Ahmadi, Farhad Hosseinpanah, and Haidar Ali Hooman. Study supervision: Fazlollah Ghofranipour and Parisa Amiri.

\section{Funding/Support}

This study was supported in part by the Tarbiat Modares University and Obesity Research Center, Research Institute for Endocrine Sciences, Shahid Beheshti University of Medical Sciences, Tehran, Iran.

\section{References}

1. Lob-Corzilius T. Overweight and obesity in childhood--a special challenge for public health. Int J Hyg Environ Health. 2007 210(5):585-9.

2. Lobstein T, Baur L, Uauy R, Iaso International Obesity TaskForce . Obesity in children and young people: a crisis in public health. Obes Rev. 2004;5 Suppl 1:4-104.

3. Freedman DS, Dietz WH, Srinivasan SR, Berenson GS. The relation of overweight to cardiovascular risk factors among children and adolescents: the Bogalusa Heart Study. Pediatrics. 1999;103(6 Pt 1):1175-82.

4. Ogden CL, Carroll MD, Curtin LR, McDowell MA, Tabak CJ, Flegal KM. Prevalence of overweight and obesity in the United States, 1999-2004. JAMA. 2006;295(13):1549-55.

5. Motlagh ME, Kelishadi R, Ardalan G, Gheiratmand R, Majdzadeh $\mathrm{R}$, Heidarzadeh A, et al. Rationale, methods and first results of the Iranian national programme for prevention of chronic diseases from childhood: CASPIAN Study. East Mediterr Health J 2009;15(2):302-14.

6. Hatami M, Taib MN, Jamaluddin R, Saad HA, Djazayery A, Chamari $\mathrm{M}$, et al. Dietary factors as the major determinants of overweight and obesity among Iranian adolescents. A cross-sectional study. Appetite. 2014;82:194-201.

7. Jalali-Farahani S, Chin YS, Amiri P, Mohd Taib MN. Body mass index (BMI)-for-age and health-related quality of life (HRQOL) among high school students in Tehran. Child Care Health Dev. 2014;40(5):731-9.

8. Whitlock EP, O'Connor EA, Williams SB, Beil TL, Lutz KW. Effectiveness of weight management interventions in children: a targeted systematic review for the USPSTF. Pediatrics. 2010; 125(2):e396-418

9. Maddah M, Rashidi A, Mohammadpour B, Vafa R, Karandish M. In-school snacking, breakfast consumption, and sleeping pat terns of normal and overweight Iranian high school girls: a study in urban and rural areas in Guilan, Iran. J Nutr Educ Behav. 2009;41(1):27-31

10. Kelishadi R, Ardalan G, Gheiratmand R, Gouya MM, Razaghi EM, Delavari A, et al. Association of physical activity and dietary behaviours in relation to the body mass index in a national sample of Iranian children and adolescents: CASPIAN Study. Bull World Health Organ. 2007;85(1):19-26.

11. Azadbakht L, Esmaillzadeh A. Dietary diversity score is related to obesity and abdominal adiposity among Iranian female youth Public Health Nutr. 2011;14(1):62-9.

12. Kamath CC, Vickers KS, Ehrlich A, McGovern L, Johnson J, Singhal V, et al. Clinical review: behavioral interventions to preven childhood obesity: a systematic review and metaanalyses of randomized trials. J Clin Endocrinol Metab. 2008;93(12):4606-15.

13. Thomas H. Obesity prevention programs for children and youth: why are their results so modest? Health Educ Res. 2006;21(6):783-95.

14. Flodmark CE, Marcus C, Britton M. Interventions to prevent obesity in children and adolescents: a systematic literature review. Int J Obes (Lond). 2006;30(4):579-89.

15. Wright ND, Groisman-Perelstein AE, Wylie-Rosett J, Vernon N Diamantis PM, Isasi CR. A lifestyle assessment and intervention tool for pediatric weight management: the HABITS questionnaire. J Hum Nutr Diet. 2011;24(1):96-100.

16. Hendricks C, Murdaugh C, Pender N. The Adolescent Lifestyle Profile: development and psychometric characteristics. J Nat Black Nurses Assoc. 2006;17(2):1-5.

17. Gillis AJ. The Adolescent Lifestyle Questionnaire: development and psychometric testing. Can J Nurs Res.1997;29(1):29-46.

18. West F, Sanders MR. The Lifestyle Behaviour Checklist: a measure of weight-related problem behaviour in obese children. Int J Pediatr Obes. 2009;4(4):266-73.

19. Amiri P, Ghofranipour F, Ahmadi F, Hosseinpanah F, Montazeri A Jalali-Farahani S, et al. Barriers to a healthy lifestyle among obese adolescents: a qualitative study from Iran. Int J Public Health. 2011;56(2):181-9.

20. Kelishadi R, Gouya MM, Ardalan G, Hosseini M, Motaghian M Delavari A, et al. First reference curves of waist and hip circumferences in an Asian population of youths: CASPIAN study. J Trop Pediatr. 2007;53(3):158-64.

21. DiIorio CK. Measurement in health behavior: methods for research and evaluation.USA: John Wiley and Sons; 2006.

22. Lawshe CH. A Quantitative Approach to Content Validity. Personnel Psychology. 1975;28(4):563-75.

23. Polit DF, Beck CT. The content validity index: are you sure you know what's being reported? Critique and recommendations. Res Nurs Health. 2006;29(5):489-97.

24. McHorney CA, Ware JJ, Lu JF, Sherbourne CD. The MOS 36-item Short-Form Health Survey (SF-36): III. Tests of data quality, scaling assumptions, and reliability across diverse patient groups. Med Care. 1994;32(1):40-66.

25. Bentler PM, Bonett DG. Significance tests and goodness of fit in the analysis of covariance structures. Psychol Bull. 1980; 88(3):588-606

26. Downes L. Motivators and barriers of a Healthy Lifestyle Scale: development and psychometric characteristics. J Nurs Meas. 2008;16(1):3-15.

27. West F, Morawska A, Joughin K. The Lifestyle Behaviour Checklist: evaluation of the factor structure. Child Care Health Dev. 2010;36(4):508-15 